\title{
The determinants of metamemory beliefs: the effect of Self-relevance and Friend-relevance. How important is anxiety?
}

\begin{abstract}
BACKGROUND
Metacognitive beliefs (beliefs about one's own possibilities) are an object of research in several clinical groups. Personality characteristics determine the contents of such beliefs.

\section{PARTICIPANTS AND PROCEDURE}

In the study of the general population, judgment of learning $(\mathrm{JOL})$ techniques were used. This technique is based on estimating the level of material (words) memorized, then learning and memorizing. There were two types of tasks used: for Self-relevance and Friend-relevance. The task was to express judgments about a friend's (he/she) beliefs (I think he/she thinks...) and about the friend's performance (I think he/she will perform...) in the described task.
\end{abstract}

\section{RESULTS}

A higher level of trait anxiety led to negative self-evaluations of one's capabilities. Higher levels of state anxiety promoted more positive assessment of the friend's possibilities.

\section{CONCLUSIONS}

Anxiety analyzed as an isolated variable does not explain the character of metacognitive self-beliefs and beliefs regarding a friend. Both our findings and the results of previous studies (3) suggest that the tendency to under-evaluate one's abilities is a frequent characteristic of metacognitive beliefs, being independent of anxiety levels. Future research should center around similar analyses of persons diagnosed with specific types of anxiety-related disorders.

\section{KEY WORDS}

metacognition/metamemory; anxiety; judgment of learning (JOL); Self-relevance; other (Friend)-relevance

organizations - Department of Clinical Psychology and Neuropsychology, Institute of Psychology, Maria CurieSkłodowska University, Lublin, Poland

AUthors' CONTRibution - A: Study design - B: Data collection - C: Statistical analysis - D: Data interpretation .

E: Manuscript preparation · F: Literature search · G: Funds collection

CORRESPONDING AUthor - Prof. Ewa Małgorzata Szepietowska, Department of Clinical Psychology and Neuropsychology, Institute of Psychology, Maria Curie-Skłodowska University, Lublin, Poland, e-mail: goszepiet@poczta.onet.pl 


\section{INTRODUCTION}

Self-beliefs regarding one's cognitive processes, i.e. beliefs in one's own possibilities and reflections on these beliefs, constitute manifestations of metacognitive processes. Factors determining the contents of these beliefs include a number of individual variables, among them cognitive, affective and social factors (Dunlosky, Serra, \& Baker, 2007; Nelson, Kruglanski, \& Jost, 1998; Szepietowska \& Gawda, 2013).

Ewa Małgorzata Szepietowska
The contents of metacognitive beliefs constitute a particularly interesting area of psychopathological research, as they are considered a factor that triggers and maintains clinical signs of various conditions (as reviewed by Szepietowska, 2013). Among many dimensions of metacognition, self-beliefs regarding one's memory constitute the most frequent subject of research. Such beliefs can manifest, inter alia, as "memory" complaints, typically considered by clinicians as an objective marker of memory impairment (Metternick, Schmidtke, \& Hull, 2009). However, research suggests that relationships between subjective evaluation one's own memory and the true performance are complex, as each of these parameters may be influenced by different variables. The self-beliefs are based on auto-observation of one's achievements, their dynamics, e.g. associated with age, comparisons with the performance of others, social stereotypes and lay knowledge of memory. Moreover, the self-evaluation of one's memory is also influenced by age, sex (Gino et al., 2010; Holmen et al., 2013; Jonker, Smits, \& Deeg, 1997; Levy, 1996; Lima-Silva \& Yassuda, 2009) and affective and personality-related factors (Cosenza, Pedona, Labella, \& Nigro, 2007), especially enhanced anxiety or depression. These relationships are interpreted in terms of the concepts of affective-cognitive schemes (e.g. Beck \& Clark, 1997). The dysfunctional schemes direct cognitive processes to a given type of stimulation (e.g. threatening stimulation), thus adjusting them to the contents of schemes (Cisler \& Koster, 2010). This is reflected by a bias at various stages of information processing (Everaert, Koster, \& Derakshan, 2012; Mathews \& Mackintosh, 1998) observed under various research conditions in individuals treated due to anxiety-related disorders (see: Coles \& Heimberg, 2002). Such individuals include in their memories contents that are associated with anxiety-stimulating events (Dalgleish \& Cox, 2002), exaggerate various threatening situations and threats (Mogg \& Bradley, 1999), and generalize (negative) beliefs regarding their memory and other aspects of their cognitive functioning. Moreover, they point to necessary use of "external" memory (notes, notebooks), believing that their own memory does not function normally. It is unclear whether this preference reflects the true poor performance of memory or is rather a strategy confirming its poor performance and thus one's self-knowledge (Comijs, Deeg, Dik, Twisk, \& Jonker, 2002; Neckar, 2009; Strober \& Esser, 2001). The results of research on relationships between a negative self-evaluation of one's performance and performance levels of individuals with anxiety are inconclusive. Although previous studies confirmed the association between negative self-perception of one's functioning and the level of anxiety (resulting from different activation of various regions of the central nervous system than in the case of individuals free from anxiety), they did not reveal a relationship between the level of anxiety and the level of cognitive performance (Coles \& Heimberg, 2002; Righi, Mecacci, \& Viggiano, 2009). The question of whether individuals with anxiety-related/depressive disorders show cognitive bias solely with regards to themselves (self-relevance) or rather can adapt another viewpoint (i.e. the perspective of an Other), i.e. disengage their attention from a given type of stimulation and from themselves (disengagement of attention) is still a matter of discussion. Previous research (Wisco \& Nolen-Hoeksema, 2010) showed that whenever individuals with anxiety evaluate competencies of another person from his/her perspective (I think that he/she thinks...), they formulate positive judgments, while their negative judgments refer solely to themselves. However, this effect is dependent on characteristics of an Other (friend, person), the primary clinical problem (depression, anxiety-related disorder) and research procedures.

\section{PARTICIPANTS AND PROCEDURE}

This study represents an attempt to illustrate the abovementioned issues. The aim of the study was to identify predictors of self-evaluated performance in memorizing verbal material, and predictors of judgments about a friend's beliefs regarding possibility of memorizing the same material ("I think that he/ she thinks...') and about the friend's performance ("I think that he/she will perform...").

The study included 124 persons from the general population (72 women and 52 men), aged 18-30 years $(M=23.4, S D=2.89)$, all right-handed, with no history of previous or current treatment, and consenting to participate in the project. The mean duration of participants' education was 15.8 years $(S D=1.9)$.

We used the following research methods.

1) Tasks based on judgment of learning (JOL) technique (Dunlosky et al., 2007; Szepietowska \& Gawda, 2013). The tasks pertain to self-evaluating the level of memorizing a given material during several attempts. This requires decision-making processes, as well as the use of working and episodic memory, allowing performance-based modification of judgments. The first task (version Self) per- 
tained to subjective evaluation of one's memory and objective evaluation of the true performance. Each participant was asked to memorize a list of 10 words (nouns) in six attempts. Before the first presentation of the list, each subject was asked to evaluate the number of words that he/she believed that he/she was able to memorize. Subsequently, the participant was presented the list and then asked to repeat as many words as possible; he/she was informed about the result. The task comprised six attempts (self-evaluation, presentation of the list, memorizing). Analyzed parameters included the total number of words a participant expected to memorize (up to 60) and the sum of truly memorized words (up to 60). During the second task (version Friend) the participant was told that the same task as described in the first stage was performed by his/her friend of the same age and sex (the participant could even choose the friend's name). Each subject was asked to judge a number of words the friend would expect to memorize (up to 60) and a number of words that would be truly memorized by the friend (up to 60).

2) Wechsler Adult Intelligence scale WAIS-R (Brzeziński et al., 2004), determining verbal skills as a predictor of metacognitive performance (Dunlosky et al., 2007).

3) Polish adaptation of the STAI questionnaire by C.D. Spielberger (X1 - state anxiety, and X2 - trait anxiety) (Wrześniewski, Sosnowski, \& Matusik, 2002).

Analysis of results included stepwise multiple regression, with self-evaluated memory, judgments about the friend's beliefs and friend's performance as dependent variables, and participant's age, the levels of state (STAI 1) and trait anxiety (STAI 2) and the score of the vocabulary subtest of WAIS-R as independent predictors.

\section{RESULTS}

The results are presented in Table 1.

When expressed as the sten values, the scores of $\mathrm{X} 1$ and X2 scales ranged between 2 and 7, i.e. between low and high levels of anxiety. Mean scores of the JOL tasks suggest that the respondents evaluated their ability of memorizing 60 words at about $79.5 \%$, whereas their true performance corresponded to $88.2 \%$. Thus, they showed a tendency to under-evaluate their performance. In turn, the mean judgments about the friend's self-evaluation and performance was $81.3 \%$ and $81.7 \%$, respectively, thus being higher than the self-evaluated and true performance of the participants. Women evaluated their performance worse than men $(M=46.3$ vs. $M=49.7, p=0.06)$ and showed higher values of both trait $(M=41.46 \mathrm{vs}$. $M=38.0, p=0.06)$ and state anxiety $(M=35.9$ vs.
Table 1

Results: mean $(M)$ and standard deviations $(S D)$ in the study group $(n=124)$

\begin{tabular}{lcc}
\hline \multicolumn{1}{c}{ Variable } & $M$ & $S D$ \\
\hline Self-evaluation & 47.70 & 6.53 \\
Self-performance & 52.90 & 4.27 \\
Friend's evaluation & 48.80 & 7.80 \\
Friend's performance & 49.07 & 9.04 \\
Vocabulary & 47.60 & 10.76 \\
STAI 1 & 34.40 & 10.09 \\
STAI 2 & 40.06 & 9.21 \\
\hline
\end{tabular}

Anxiety and meta-memory beliefs

$M=32.3, p=0.06)$. Also the other analyzed parameters did not differ significantly between women and men. The results of multiple regression for the "self-evaluation" variable are presented in Table 2 . Due to the lack of significant differences between the scores of women and men, the results of the regression analysis were not adjusted for gender.

Interactions between the level of trait anxiety, verbal skills/semantic knowledge and true performance of the participants proved to be significant determinants of their self-evaluated memory. These variables together explained $28 \%$ of variance in the dependent variable: the true performance proved to be better predictor of the self-evaluation than trait anxiety and semantic knowledge. The lower the level of trait anxiety and the higher the levels of performance and semantic knowledge, the better the self-evaluated memory.

The judgments about the friend's beliefs were an outcome of an interaction between true performance, its self-evaluation and state anxiety level of the participants. Interactions between these variables explained ca. $20 \%$ of variance in the dependent variable. True performance and its self-evaluation turned out to be better predictors of the dependent variable, whereas the level of state anxiety, although significant too, was of lesser importance. Higher levels of performance and its self-evaluation, as well as a higher level of state anxiety of the respondents were associated with better judgment about the friend's beliefs. In turn, the judgments about the friend's performance turned out to be determined by an interaction between the level of state anxiety and true performance of the participants. These two parameters together explained $17 \%$ of variance in the dependent variable. The higher the level of state anxiety and the better the participant's performance, the better the judgment about the friend's performance (Table 3). 
Table 2

Stepwise multiple regression for "Self-evaluation" variable

\begin{tabular}{|c|c|c|c|}
\hline \multirow{2}{*}{ Predictors } & \multicolumn{3}{|c|}{ Self-evaluation } \\
\hline & Step $1(\beta)$ & Step $2(\beta)$ & Step $3(\beta)$ \\
\hline Self-performance & $0.49(.001)^{* * *}$ & $0.46(.001)^{* * *}$ & $0.40(.001)^{* * *}$ \\
\hline Vocabulary & 0.13 & 0.17 & $0.17(.04)^{*}$ \\
\hline Age & 0.05 & 0.04 & 0.03 \\
\hline STAI 1 & -0.13 & -0.03 & -0.008 \\
\hline STAI 2 & -0.18 & $-0.18(.02)^{*}$ & $-0.21(.009)^{* *}$ \\
\hline$R^{2}$ corrected & 0.24 & 0.26 & 0.28 \\
\hline$F(p)$ & $39.05(.001)^{* * *}$ & $22.88(.001)^{* * *}$ & $17.15(.001)^{* * *}$ \\
\hline
\end{tabular}

Table 3

Stepwise multiple regression for "Friend's evaluation" and "Friend's performance" variables

\begin{tabular}{|c|c|c|c|c|c|}
\hline \multirow[t]{2}{*}{ Predictors } & \multicolumn{3}{|c|}{$\begin{array}{l}\text { Friend's evaluation } \\
\text { "I think that he/she thinks..." }\end{array}$} & \multicolumn{2}{|c|}{$\begin{array}{l}\text { Friend's performance } \\
\text { "I think that he/she will perform..." }\end{array}$} \\
\hline & Step 1 & Step 2 & Step 3 & Step 1 & Step 2 \\
\hline Self-performance & $0.38(.001)^{* * *}$ & $0.26(.007)^{* *}$ & $0.27(.005)^{* *}$ & $0.34(.001)^{* * *}$ & $0.37(.001)^{* * *}$ \\
\hline Self-evaluation & 0.24 & $0.24(.01)^{* *}$ & $0.27(.004)^{* *}$ & 0.05 & 0.09 \\
\hline STAI 1 & 0.16 & 0.19 & $0.19(.02)^{*}$ & 0.26 & $0.26(.002)^{* *}$ \\
\hline STAI 2 & 0.11 & 0.16 & 0.06 & 0.16 & -0.01 \\
\hline Vocabulary & -0.09 & -0.13 & -0.14 & -0.04 & -0.05 \\
\hline Age & -0.02 & -0.03 & 0.005 & -0.04 & 0.002 \\
\hline$R^{2}$ corrected & 0.14 & 0.17 & 0.20 & 0.11 & 0.17 \\
\hline$F(p)$ & $20.30(.001)^{* * *}$ & $13.91(.001)^{* * *}$ & $11.59(.001)^{* * *}$ & $15.86(.001)^{* *}$ & $13.68(.001)^{* * *}$ \\
\hline
\end{tabular}

\section{DISCUSSION}

We showed that self-evaluated memory was determined by interactions between true performance, semantic resources and level of trait anxiety; a higher level of trait anxiety was associated with worse self-evaluation of one's memory. In turn, the self-evaluated memory and the level of state anxiety proved to be determinants of the friend's beliefs and performance. Higher levels of state anxiety were associated with ascribing greater abilities to a friend. We observed common feature of all the participants, namely all of them under-evaluated their performance (which was in fact higher than the self-evaluated memory); also the judgments on the friend's beliefs were better than the self-evaluated memory. The tendency to lower self-evaluation was characteristic for women, who also showed higher levels of state and trait anxiety.

It is noteworthy that this study included participants who did not receive any psychiatric treatment; thus any generalization of the results to all persons with anxiety-related disorders requires further analyses. We found that anxiety is not the only predictor of self-evaluated memory and judgments about a friend's beliefs. Nevertheless, data from the literature suggest that inappropriate self-evaluation of one's abilities is crucial for development of psychopathological symptoms and persistence thereof. Mechanisms underlying such beliefs are explained in terms of various metacognitive theories (e.g. theory of mind) or mentalizing, emphasizing the role of processes enabling one to predict and explain behaviors and states of mind of oneself and others (Paulus \& Stein, 2010). Individuals showing higher levels of anxiety usually evaluate themselves as less competent and deprived in cognitive skills (Mathews $\&$ MacLeod, 2005). Only a few previous studies have addressed the issue of judging the cognitive skills of others. The results are inconclusive; while some data point to difficulties in disengagement of attention from self in favor of judgment from others' perspective, the results of other studies suggest that the 
presence of such a phenomenon is determined by the situation, type of stimulation and traits of the others. Persons showing high levels of anxiety typically do not have problems with predicting states of mind of others, e.g. understanding their sense of humor, but are hyper-alert, interpreting their reactions in the context of threatening stimulation (Samson, Lackner, Weiss, \& Papousek, 2012). Anxiety or depressed mood may decrease cognitive involvement in execution of a task, promote critical self-thinking, and reduce the repertoire of strategies important for completing the task; as a result, this negative affect may persist in the case of anxiety-stimulating tasks (such as being evaluated or evaluating others) or achieving poor scores (Szepietowska \& Gawda, 2013). Many previous studies have documented discrepancies between the mechanisms of self-evaluation and evaluation of others, and identified anxiety as a significant moderator of these processes. Individuals presenting negative affect may show a tendency to interpret the behaviors of others in the context of negative attributes (e.g. depending on a task's instruction). The role of state anxiety is worth emphasizing, as this trait proved to exert a positive effect on the judgments about the friend's beliefs. State anxiety can be an intervening factor between an anxiety-related cognitive scheme and the situation of being examined; individuals presenting with a higher level of anxiety perceive the latter situation as threatening as it is associated with the necessity of evaluating other persons. This is reflected by discrepancies between the results of self-evaluation and evaluation of the friend. Also a tendency to an association between sex and metacognitive beliefs is worth emphasizing. We found that women presented higher levels of both state and trait anxiety and observed a tendency to negative self-evaluation. These observations are consistent with suggestions that these are women who are characterized by higher levels of negative emotionality, a higher degree of concentration on themselves and greater negativism during self-evaluation (Gawda \& Szepietowska, 2013). Also the true performance and semantic knowledge proved to be significant predictors of our participants' judgments. The techniques, such as JOL, allow performance-based modification of beliefs through involvement of execution and control processes (Hertzog, Dixon, \& Hultsch, 1990). In turn, a higher level of verbal skills promotes auto-reflection, co-creates self-representation, and improves efficiency of social interactions, thus stimulating reflection of the others (Dunlosky et al., 2007).

\section{CONCLUSIONS}

In conclusion, anxiety analyzed as an isolated variable does not explain the character of metacognitive self-beliefs and beliefs regarding a friend. Both our findings and the results of previous studies (Szepietowska \& Gawda, 2013) suggest that the tendency to under-evaluate one's abilities is a frequent characteristic of metacognitive beliefs, being independent from anxiety levels. Future research should center around similar analyses of persons diagnosed with specific types of anxiety-related disorders.

\section{REFERENCES}

Beck, A. T., \& Clark, D. A. (1997). An information processing model of anxiety: automatic and strategic processes. Behaviour Research and Therapy, 35, 49-58.

Brzeziński, J., Gaul, M., Hornowska, E., Jaworowska, A., Machowski, A., \& Zakrzewska, M. (2004). Skala Inteligencji $D$. Wechslera dla dorostych. Wersja zrewidowana - re normalizacja WAIS - $R(P L)$ [WAIS-R $(\mathrm{PL})$ - revised version. Renormalization]. Warszawa: PTP.

Cisler, J. M., \& Koster, E. H. (2010). Mechanisms of attentional biases towards threat in anxiety disorders: An integrative review. Clinical Psychology Review, 30, 203-216.

Coles, M. E., \& Heimberg, R. G. (2002). Memory biases in the anxiety disorders: current status. Clinical Psychology Review, 22, 587-627.

Comijs, H. C., Deeg, D. J., Dik, M. G., Twisk, J. W., \& Jonker, C. (2002). Memory complaints: the association with psycho-affective and health problems and the role of personality characteristics. A 6-year follow-up study. Journal of Affective Disorders, 72, 157-165.

Cosenza, M., Pedona, R., Labella, A., \& Nigro, G. (2007). Metamemory and personality traits. Rivista di Psicologia Clinica, 2, 136-146.

Dalgleish, T., \& Cox, S. (2002). Memory and emotional disorders. In: A. D. Baddeley, M. Kopelman, \& B. Wilson (eds.). The Handbook of Memory Disorders (pp. 437-457). London: Wiley and Sons.

Dunlosky, J., Serra, M., \& Baker, J. (2007). Metamemory. In: F. Durso (ed.). Handbook of Applied Cognition ( ${ }^{\text {nd }}$ ed., pp. 137-161). London: John Wiley and Sons.

Everaert, J., Koster, E. H., \& Derakshan, N. (2012). The combined cognitive bias hypothesis in depression. Clinical Psychology Review, 32, 413-424.

Gawda, B., \& Szepietowska, E. M. (2013). Impact of unconscious emotional schemata on verbal fluency - sex differences and neural mechanisms. NeuroQuantology, 11, 443-450.

Gino, S., Mendes, T., Maroco, J., Ribeiro, F., Schmand, B. A., de Mendonca, A., \& Guerreiro, M. (2010). Memory complaints are frequent but qualitatively different in young and elderly healthy people. Gerontology, 56, 272-277. doi: 10.1159/000240048.
Anxiety and meta-memory beliefs 
Ewa Małgorzata Szepietowska
Hertzog, C. H., Dixon, R., \& Hultsch, D. (1990). Relationship between metamemory, memory predictions, and memory task performance in adults. Psychology and Aging, 5, 215-227.

Holmen, J., Langball, E., Midthjell, K., Holmen, T., Fikseaunet, A., Saltvedt, I., \& Tambs, K. (2013). Gender differences in subjective memory impairment in a general population: the Hunt study, Norway. BMC Psychiatry, 1, 19.

Jonker, C., Smits, C., \& Deeg, D. (1997). Affect-related metamemory and memory performance in a population-based sample of older adults. Gerontology, 23, 115-128.

Levy, B. (1996). Improving memory in old age through implicit self-stereotyping. Journal of Personality and Social Psychology, 71, 1092-1102.

Lima-Silva, T., \& Yassuda, M. (2009). The relationship between memory complaints and age in normal aging. Dementia and Neuropsychologia, 3, 94-100.

Mathews, A., \& Mackintosh, B. (1998). A cognitive model of selective processing in anxiety. Cognitive Therapy and Research, 22, 539-560.

Mathews, A., \& MacLeod, C. (2005). Cognitive vulnerability to emotional disorders. Annual Review of Clinical Psychology, 1, 167-195.

Metternick, B., Schmidtke, K., \& Hull, M. (2009). How are memory complaints in functional memory disorder related to measures of affect, metamemory and cognition. Journal of Psychosomatic Research, 66, 435-444.

Mogg, K., \& Bradley, B. (1999). Selective attention and anxiety: a cognitive-motivational perspective. In: T. Dalgleish \& M. Power (eds.). Handbook of Cognition and Emotion (pp. 145-170). London: John Wiley and Sons.

Neckar, J. (2009). Lepszy od innych, a może wciąż taki sam. Tendencyjność w budowaniu samowiedzy [Better than others, and may still the same. Bias in the construction of self-knowledge]. In: A. Niedźwieńska \& J. Neckar (eds.). Poznaj samego siebie czyli o źródtach samowiedzy [Know yourself: on the sources of self-knowledge] (pp. 194-212). Warszawa: Academica SWPS.

Nelson, T. O., Kruglanski, A. W., \& Jost, J. T. (1998). Knowing thyself and others: progress in metacognitive social psychology. In: V. Y. Yzerbyt, G. Lories \& B. Dardenne (eds.). Metacognition: Cognitive and Social Dimensions (pp. 69-89). Thousand Oaks, CA: Sage.

Paulus, M. P., \& Stein, M. B. (2010). Interoception in anxiety and depression. Brain Structure and Function, 214, 451-463.

Righi, S., Mecacci, L., \& Viggiano, M. P. (2009). Anxiety, cognitive self-evaluation and performance: ERP correlates. Journal of Anxiety Disorders, 23, 1132-1138.

Samson, A., Lackner, H., Weiss, E., \& Papousek, I. (2012). Perception of other people's mental states affect humor in social anxiety. Journal of Behavior Therapy and Experimental Psychiatry, 43, 625-631.

Strober, J., \& Esser, K. (2001). Test anxiety and metamemory: general preference for external over internal information storage. Personality and Individual Differences, 30, 775-781.

Szepietowska, E. M. (2013). Metapamięć. Perspektywa psychologiczna i kliniczna [Metamemory. The psychological and clinical view]. Warszawa: Wyd. Difin.

Szepietowska, E. M., \& Gawda, B. (2013). Metapamięć: jakie są uwarunkowania sądów o własnej pamięci? Badania pilotażowe [Metamemory: what are the determinants of beliefs about one's own memory?]. Psychologia-Etologia-Genetyka, 27, 41-57.

Wisco, B. E., \& Nolen-Hoeksema, S. (2010). Interpretation bias and depressive symptoms: The role of self-relevance. Behaviour Research and Therapy, 48, 1113-1122.

Wrześniewski, K., Sosnowski, T., \& Matusik, D. (2002). Inwentarz Stanu i Cechy Lęku [State and Trait Anxiety Inventory]. Warszawa: Pracownia Testów Psychologicznych PTP. 